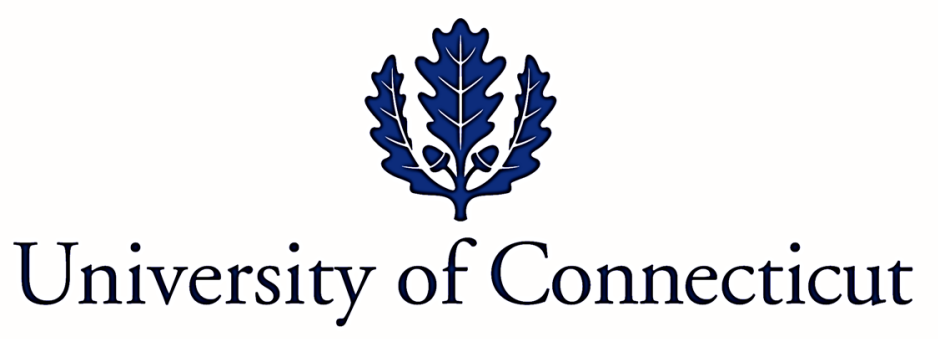

Department of Economics Working Paper Series

\title{
The Impact of Stock Market Fluctuations on the Mental and
}

\section{Physical Wellbeing of Children}

by

Chad Cotti

University of Wisconsin Oshkosh

David Simon

University of Connecticut

Working Paper 2016-28

June 2016

365 Fairfield Way, Unit 1063

Storrs, CT 06269-1063

Phone: (860) 486-3022

Fax: (860) 486-4463

http://www.econ.uconn.edu/

This working paper is indexed in RePEc, http://repec.org 


\title{
The Impact of Stock Market Fluctuations on the Mental and Physical Wellbeing of Children
}

\author{
Chad Cotti \\ Department of Economics, University of Wisconsin Oshkosh \\ cottic@uwosh.edu \\ David Simon \\ Department of Economics, University of Connecticut \\ David.simon@uconn.edu
}

June 6, 2016

The stock market crash of 2008 caused a severe impact to households. Earlier research has explored the impacts of a stock market crash on life wellbeing, psychological stress, and adult health behaviors. We extend this literature by documenting impacts of stock market fluctuations on a range of child outcomes; including effects on both mental and physical health. We show a negative effect of a market crash on hospitalizations, child reported health status, sick days from school, and emotional difficulties. Both graphical and regression based analysis reveal that our results are not driven by a pre-trend of declining child health before the market crash.

We would like to thank the participants at the University of Connecticut Health Economics seminar series for their insightful comments on this paper. We would like to thank Mark McInerney for his excellent research assistance. All errors are our own. 


\section{Introduction}

Severe fluctuations in the stock market could potentially have widespread implications for the wellbeing of American families and children. In particular, the U.S. stock market crash of 2008 was extremely severe, as the Dow Jones Industrial Average (DJIA) fell nearly 50\% from late 2007 to early 2009. The direct wealth impacts of this collapse were widespread, as over $60 \%$ of the U.S. population owned investment stock at the beginning of the 2008 recession (Gallup Inc., 2011). Not surprisingly, the substantial variation in wealth and financial stability created by this market decline has promoted the study of many interesting behavioral and psychological questions. This paper attempts to quantify the impact of the stock market crash on one important measure of family wellbeing: the health of children. One reason for focusing on child health, is that children are a particularly vulnerable and relatively under studied demographic group. Studies on child health are additionally of particular interest because child health is a strong predictor for future labor market productivity (Almond and Currie, 2011). At the same time there is limited evidence on a causal relationship between family socioeconomic conditions and child outcomes.

Earlier work reveals the depth and breadth of the impact of financial market fluctuations on health outcomes and behavior, but have only focused on adult populations. In particular, researchers have found that the market crash led to large declines in life evaluation (Deaton, 2011), meaningful increases in psychological stress (McInerney et al., 2012), and sharp increases in negative health/behavioral effects (Engelberg and Parsons, 2015, Cotti, Dunn, and Tefft, 2015). However, if there are notable impacts on adult health, behavior, and mental wellbeing, the impact of fluctuations in financial markets may also impact the health and wellbeing of children. Parental stress from a financial crisis or loss of assets in a household may spillover to impact the mental and physical well-being of children. Furthermore, increases in negative parental health behaviors, such as drinking, could weaken child health through decreased oversight and resulting injuries. 
For example, early life exposure to cigarette smoke has been shown to increase sick days from school and medical care utilization (Simon, 2015). However, it remains unclear if the negative impacts identified on adult health and behavior would carry over to children's health and wellbeing, or if lost future wealth (or the perception of wealth) may conversely lead to a reduction in children being exposed to risky activities, greater parental attention, and/or parental time investments, all of which may improve the immediate health outcomes of children.

In this paper we attempt to directly address these issues by investigating the impact of stock market fluctuations on the contemporaneous health of children; particularly capitalizing on the large swings in value characterized by stock prices of the time period from $2004-2011$. Understanding how children's health is impacted is important to understanding the potential impact of the financial crisis on population health and children's wellbeing. Our primary findings are that large declines in the stock market harm child health, as seen in increases in hospitalizations, decreases in self-reported health, and increased emotional difficulties. We find no statistically significant effect of fluctuations on increasing sick days from school, though the sign on this variable is consistent with the crash harming health.

Our empirical specification compares fluctuations in the stock market with contemporaneous changes in child health, while independently controlling for the unemployment rate. The coefficient on the log Dow Jones is identified primarily off of the increase in the stock market leading up to the 2008 financial crisis, followed by a steep decline during the 2008 financial crisis and a subsequent sharp rebound in stock beginning around late 2009. A careful graphic analysis shows that a wide range of child health outcomes follows a corresponding pattern. Of particular importance is that there is no evidence of a pre-trend in health before the 2008 stock market crash driving the results. Section II discusses background and motivation. Section III 
discusses the empirical methodology, model specification, and summarizes the data. Section IV presents the results and discusses the findings. Section V concludes.

\section{Background and Motivation}

In thinking about the impact of financial markets on health, it is important to recognize the contribution of previous research, which has identified that population health is meaningfully impacted by macroeconomic fluctuations, specifically recessionary effects (typically measured by changes in unemployment rates). For instance, it has been well documented that all-cause mortality in developed economies tends to decrease when the unemployment rate increases. ${ }^{1}$ It is hypothesized that behaviors associated with increased mortality, such as consumption of alcohol and cigarettes, are sufficiently normal so that health actually improves when the economy worsens. This explanation is consistent with empirical studies showing that the decline in mortality during times of higher unemployment is concentrated in acute causes, e.g., motor vehicle accidents and injuries, rather than slowly developing causes, such as cancer or kidney disease (Evans \& Moore, 2012). ${ }^{2}$ Empirical investigation of such behaviors confirms that changes in these "pathway" causes of acute mortality do indeed fall. Specifically, numerous studies have shown that risky behaviors such as alcohol consumption (Cotti, Dunn, \& Tefft, 2015; Ettner, 1997; Freeman, 1999; Ruhm \& Black, 2002; Ruhm, 1995), cigarette consumption (Charles \& DeCicca, 2008; Ruhm, 2000, 2005), and drunk driving (Cotti \& Tefft, 2011), are negatively related to the unemployment rate in the United States.

\footnotetext{
1 This pattern has been documented in the United States (Ruhm, 2000), the European Union (Krüger \& Svensson, 2008; Neumayer, 2004; Tapia Granados, 2005), and Japan (Tapia Granados, 2005).

${ }^{2}$ An important exception to the counter-cyclical relationship between macroeconomic performance and mortality is suicide, which is generally found to be positively related to both the unemployment rate (Ruhm, 2000), other measures of job loss and the duration of unemployment (Classen \& Dunn, 2012).
} 
In spite of a large literature on unemployment and health, there is little research on how child health responds to fluctuations in aggregate economic conditions. Dehejia and Lleras-Muney (2004) found that recessions lead to improvements in early life health such as higher birthweight and lower rates of infant mortality. They attribute this change to improvements in the opportunity cost of time for women. Similarly, the mortality rates identified by Ruhm, have also been shown to occur throughout the age distribution, including effects on children through the age of 17 (Stevens et al., 2015). Finally, fertility decreases during recessions which could indirectly affect the maternal and child health within a family (Schaller, 2015). There has been conflicting estimates of the effects of the unemployment rate on the risky behavior of teens with some studies finding that alcohol, drug use, and male weight increase with a weaker economy (Arkes, 2007), and with other studies finding decreases in teen alcohol use, sexual activity, and female weight gain (Arkes, 2009).

One particularly relevant study on children is Page, Schaller, and Simon (2015) which studies the relationship between economic conditions, and child health using the National Health Interview Survey (NHIS). While the authors find little evidence of overall effects of economic conditions on child health, this masks gender specific differences: with child health improving when male specific business cycle indicators improve and declining with female specific business cycle indicators. However, none of these studies look at the impact of the stock market on child outcomes and given wide range of findings, it remains very unclear how changes in the stock market may affect children.

On the surface, one may assume that improved health outcomes during economic downturns would analogously suggest that health may also improve in response to a decline in stock prices. Yet, recent research on this specific issue on adult populations has shown the opposite 
effect. Specifically, during the 2008 stock market crash, Americans reported large declines in life evaluation (Deaton, 2011); exhibited increased symptoms of depression and poor mental health (McInerney et al., 2012); experienced a spike in hospitalizations for psychological disorders (Engelberg and Parsons, 2014), and engaged in more cigarette smoking, binge drinking, and fatal car accidents involving alcohol (Cotti, Dunn, \& Tefft, 2015). Recent research on stock market fluctuations has also found that declines in the stock market causes physical and mental health to deteriorate among the elderly (Schwandt, 2014).

Becker (2007) argues that exogenous events that impact individual attitudes about the future will impact behavioral choices. To the extent that fluctuations in stock indices influence expectations of future economic conditions, then the identification of a negative relationship between rates of depression, overall life valuation, and important health-related behaviors with the stock market is sensible. So, a possible explanation for the difference between the recessionary (unemployment rate) effects and stock market effects is that, while fluctuations in the unemployment rate capture contemporaneous economic constraints faced by households, fluctuations in the stock market may predominantly convey information about the future economic environment. Hence, changes in expected future wealth may impact behavior, as the research on adults has demonstrated (Cotti, Dunn, and Tefft, 2015).

Moreover, one might hypothesize that the documented changes in psychological stress and depression among adults (Deaton, 2011; McInerney et al., 2012) or sharp increases in negative health outcome and poor heath behaviors among adults ((Engelberg and Parsons, 2015, Cotti, Dunn, and Tefft, 2015) will lead to reduction in children's health outcomes as well. However, the impact on children could also be very different from that of adults. Ultimately the impact is not well understood and, given the literature, deserves attention. 
Further, the sub-populations of children that are impacted will differ based on the mechanisms by which market fluctuations impact behavior. For example, if the stock market influences child outcomes due to a decrease in future expected income, then the effects are likely to be concentrated on stock holders; particularly children from higher socio economic status households. On the other hand, if a crash in the stock market hurts children through generating stress caused by new information about the overall health of the economy, then this is likely to more strongly impact those children who are most vulnerable; children from low socio-economic status backgrounds. Naturally, these mechanisms are not mutually exclusive and both stock holders and non-stock holders could reasonably be effected by fluctuations in the Dow Jones. Given the emerging research on stock market indices and negative health outcomes/behaviors, investigating how market fluctuations impact child health outcomes, utilization, and behavior (after accounting for contemporaneous economic conditions) is a natural area of further study.

\section{Data}

In this paper we use repeated cross sections from 2004-2012 of the National Health Interview Survey (NHIS) to investigate the impact of stock market fluctuations on child health. The NHIS is a large, nationally representative, monthly survey used to track the health trends of the United States population. The NHIS provides data on $34,000-40,000$ families in a year. A significant advantage of the survey is that it occurs at the household-level, so we are able to link children with the characteristics of their mothers and fathers.

Household characteristics that we utilize include family income (in bins), insurance coverage, mother's education, and race. Controlling for these characteristics allow us both to absorb observable differences between families that might be correlated with health and to investigate potential mechanisms for our results. For example, by controlling for insurance status 
we remove changes in insurance as a potential pathway by which stock fluctuations influence health. When the child is too young or otherwise unable to participate in the survey, answers are provided by a knowledgeable adult, who is the child's parent more than 90 percent of the time. We include all children between the ages of 0 to 17 in the sample depending on the outcome. ${ }^{3}$

When looking at indicators of child health, we attempt to limit ourselves to measurable outcomes that are likely to respond to sudden changes in family income. Depending on the health measure under investigation, we make use of health outcomes available in two of the surveys embedded in the NHIS. First, we use outcomes from the Person-Core questionnaire which includes demographic and health data on every member (and child) in the household. Specifically, in the person-core questionnaire we measure an indicator of a child being hospitalized in the past 12 months. Hospitalizations has the advantage of being relatively objective and based on events that are unlikely to be forgotten. In addition, the person-core file has information on parent reported rank of the health of their children (on a scale of 1-5, with 1 being excellent and 5 being poor). Of note, roughly $50 \%$ of the sample reports that their children are in excellent health, making "excellent health" a natural way to bifurcate the data. That being said, the results follow a similar pattern when we use the 1-5 point scale of reported health as the dependent variable.

Additional information on child health outcomes is gathered in the sample child questionnaire, where one child per household is randomly selected and asked more detailed questions about their health and well-being. In this survey, there is a count of the number of sick days from school in the last 12 months. We additionally look at an outcome that captures whether the child has experienced emotional difficulties in the last 12 months. Table 1 shows means and

\footnotetext{
${ }^{3}$ We are limited to looking at ages 4 to 17 for emotional difficulties because this question is not asked of younger children. Similarly, we are asked to look at ages 5 to 17 for school related outcomes such as sick days from school.
} 
standard deviations for the variables used in our paper including both outcomes and demographic/socio economic controls.

For our principle measure of fluctuations in the U.S. stock market, we selected the Dow Jones Industrial Average index (DJIA), a market index constructed from the stock prices of 30 manufacturers of industrial and consumer goods, to summarize the market. The DJIA is highly correlated with other broad stock market indices, e.g., the NASDAQ and S\&P500, and it is the most widely cited market index in newspapers, television, and the internet. ${ }^{4}$ Specifically, to create our main independent variable we use the natural log of the DJIA monthly mean daily market closing index ${ }^{5}$, aggregated by month. The DJIA data series was downloaded from the St. Louis Fed's FRED Economic Data web site. ${ }^{6}$

In relating the DJIA index to the NHIS health outcome data, we must recognize that the NHIS questions are generally retrospective. For example, "hospitalization" tracks if the child visited the emergency room in the past 12 months. As a result, we utilize the mid-point value of the DJIA index time series in the corresponding 12 month period (i.e. the six-month of the DJIA index). Results prove robust to variations on this scheme.

Lastly, we also merge in data on national unemployment rates, extracted from the Bureau of Labor Statistics, U.S. Department of Labor, to account for impacts of fluctuations in the unemployment rate on health outcomes (also lagged six-months in the same fashion as the DJIA). Figure 1 graphs the quarterly average of the log Dow Jones closing value concurrently with the quarterly average of the monthly national unemployment rates. It is critical for our study that we

\footnotetext{
${ }^{4}$ For a more complete summary of the DJIA see http://www.djaverages.com/index.cfm?go=industrial-overview

5 The natural $\log$ is used instead of the level for ease of interpretation. Deflation of the market index is not necessary because when logged the inflators are transformed to annual constant shifts in the log index, which are then absorbed by the year indicator variables included in each regression model.

${ }^{6}$ http://research.stlouisfed.org/fred2/series/DJIA/
} 
separately identify the effect of the stock market from changes in the unemployment rate. Looking at figure 1, while the two series are correlated, there is also independent variation between them. Notably, the stock market recovered much more quickly after the financial collapse, while the unemployment rate remains high through the early $2000 \mathrm{~s}^{7}$. Starting in 2004 , there is an increase in the Dow Jones during the period of economic prosperity of the mid-2000s. This is followed by a steep decrease in late 2008, along with a subsequent rebound in the stock market in 2010. Figure 1 shows that the unemployment rate was also trending downwards relative to the financial collapse, though not at as fast of a rate as the upward trend in the value of the Dow Jones. Ultimately, our regression models are testing for a similar sudden decrease followed by a rebound in child health outcomes that occurs concurrently with changes in the stock market.

\section{Empirical Strategy}

In investigating how changes in the DJIA impact a range of child outcomes, we estimate versions of the following empirical model:

$$
\text { 1) } Y_{i t}=\beta_{1} M_{t}+\beta_{2} U_{t}+\beta_{i t} X_{i t}+\gamma+\tau+\varepsilon_{i t}
$$

Where $Y_{i t}$ is the health of child $i$ which is reported at year-month $t$. The primary variables of interest are represented by $M_{t}$ which summarizes the U.S. stock market. Specifically, we define $\mathrm{M}_{t}$ as the natural log of the monthly average daily close of the DJIA index lagged 6-months at year-month, and $U_{t}$ is the corresponding national unemployment rate lagged 6-months. $\gamma$ is a vector of year fixed effects. Including year fixed effects insures that the impacts of the stock market on child health only reflects within year changes in child health. Further, $\tau$ is vector of month fixed effects; conditioning on month allows us to absorb seasonal variation in child health.

\footnotetext{
${ }^{7}$ Because of this independent variation, the correlation coefficient between the log monthly closing Dow Jones and the monthly unemployment rate in our sample is only -0.21 .
} 
In this model $\beta_{1}$ is identified off of fluctuations in the stock market which are independent of changes in the unemployment rate. One concern with this strategy is that if there was a downward trend in child health prior to the stock market crash, this could cause a spurious correlation between health and stock market fluctuations. We address this both with a careful graphic analysis of the trends in health relative to the stock market crash and by adding a monthly national linear trend as a robustness check.

Finally, $\mathrm{X}_{\mathrm{it}}$ includes demographic and socio-economic controls. Our principle specification includes controls for child age (in categories: 0-2, 5-7, 8-11, 12-14, and 15-17), mother's age (in categories: 18 - 25, 26-35, 36-45, 46 and older), mother's education (high school dropout, high school or some college, and college education or more), race (black, white, Hispanic, other), an indicator for the child's mother being married, insurance status, maternal employment, and family income (in bins of 0 to $\$ 34,999 ; 35,000$ to 74,999 ; and 75,000 or more ${ }^{8}$ ). We additionally test the robustness of our results to variations on this specification. To account for correlation within time periods in child health, standard errors are clustered at the year-month level.

Throughout our empirical analysis, the dependent variables are often dichotomous indicators, such as whether the child is in excellent child health, but can also be a level measure, such the number of sick days from school. For clarity, we will estimate linear models for all of our outcomes. However, we also demonstrate that the results for our dichotomous outcomes are robust to using probit models.

\section{Results}

\footnotetext{
${ }^{8}$ Unfortunately, income in the NHIS person file is fairly poorly measured. Income is only reported in bins and the bins are not perfectly consistent over years, but has been standardized for use in our analysis.
} 


\section{a. Baseline Estimates}

Before discussing our regression results, we first present a graphic analysis of how our child health measures fluctuate with the log of the Dow Jones. As discussed above, in this analysis we compare the 6-month lagged Dow Jones with retrospective reports of health, allowing us to roughly match the changes in the two variables. Figure 2 presents this in year-quarter time for the "excellent health" outcome. Figure 2 shows that reported child health and the Dow Jones series follow fairly similar patterns. From 2004 through the first quarter of 2008, reported excellent health is increasing with the log of the Dow Jones. After the stock market crash, reported excellent health continues to increase for several months before declining with the Dow Jones, reaching its minimum point several months after the trough of the crash. This suggests a somewhat lagged impact of the effect of the crash on excellent health (consistent with the retrospective nature of the NHIS questions). Finally, both health and the stock market improve together in the final part of the sample. It is particularly important to note that we do not see a downward trend in health in the quarters leading up to the stock market crash. Such a confounding pre-trend would be one sign that our results were caused by something other than the stock market. While, Figure 2 shows no evidence of a confounding pre-trend, nevertheless, we will verify this in a formal sensitivity analysis.

Figure 3 performs the same analysis, but across all our child health outcomes of interest. Many of the outcomes are more extreme and have smaller means than excellent health status, making the graphs much noisier. We dealt with this by aggregating the health outcomes into yearly rather than year-quarter bins, though regardless of the aggregation method the graphs follow the same overall pattern. Generally, across these outcomes the pattern is one such that we see health declining around the time of the market crash and then improving with the recovery. In the case 
of reported excellent health this is the more aggregated version of figure 2 above. For sick days, and emotional difficulties, we also see these indicators of poor mental and physical health increasing with the market crash. It is worth noting that reported emotional difficulties jump around slightly more than the other outcomes. The fluctuation of hospitalizations with the stock market can be seen more clearly when graphing the residuals in appendix figure A-1 (described below).

A closer approximation to our identifying variation it is to show the trends of the regression corrected residuals instead of the above graphs. This is done by regressing the unemployment rate, year fixed effects, and month fixed effects on each of our measures of child health. We then predict and graph the residuals for each health outcome next to the residuals of the log Dow Jones (predicted from a corresponding regression). These graphs are shown in Appendix Figure A-1. We were encouraged to see that the graphs of the residuals also suggests that as the stock market declines, child health deteriorates across our four measures.

In order to more formally analyze the impact of market fluctuations on child health, we now switch to our regression based analysis. Table 2 reports results for a set of NHIS outcomes and their association with stock market fluctuations. The key right hand side variable is the natural $\log$ of the monthly average daily close of the DJIA index. Overall, the results suggest that declines in the stock market negatively impact child health. Specifically, estimates suggest that during poor market performance, overall "excellent" health status meaningfully declines. Similarly, the indicators of poor health: hospitalizations, emotional difficulties, and sick days from school all increase, although the latter isn't statistically significant. Interestingly, these outcomes are notably consistent with recent work studying the health effects of the market declines on adults (McInerney et al., 2012; Engelberg and Parsons, 2015). In particular, the statistically significant estimates 
suggest that, during a month in which the DJIA is $10 \%$ lower, the likelihood of hospitalization increases by 0.49 percentage points, the likelihood of a parent reporting their child as having excellent health status decreases by 0.84 percentage points, and the likelihood of a child having emotional difficulties increases by 0.48 percentage points, ceteris paribus. These are quite meaningful effects when considered against the mean of each value and in the context of a very large stock market crash. For example, these estimates suggest that a 50\% decline in the DJIA (as was observed in 2008-2009), would (relative to their respective means) result in a $43 \%$ increase in the hospitalization rate, a $47 \%$ increase in the likelihood that a child is reported as having meaningful emotional difficulties, and a $7.6 \%$ decrease in parent's classifying their children as having "excellent" overall health status.

As our aim is to isolate stock market effects independent of business cycle factors previously identified as influencing health behaviors, in all models we control for the unemployment rate. Many of the unemployment rate coefficients are not precisely estimated, but when significant they are consistent with previous work reporting that individuals generally participate in healthier behaviors as economic conditions, proxied by state-level unemployment, tend to worsen (Ruhm, 2000).

\section{b. Robustness}

To conclude our initial analysis, we explore the robustness of the above results to reasonable changes in our empirical specification and estimation approach. First, while the model highlighted in Table 2 is our preferred specification, we demonstrate in Table 3 that the results are very similar when using alternate specifications. Specifically, for each outcome measure, we begin by estimating the model without measures of insurance status, employment status, and income. As we systematically introduce these covariates there are only very small changes in the coefficients 
on the Dow Jones. ${ }^{9}$ Finally, we show that our results do not change after accounting for a national month-year linear time trend that would absorb any trends in child health.

Next, we engage in a falsification test where we lead the DJIA treatment variable by 12months. ${ }^{10}$ By putting in a lead of the stock market measure, we are essentially specifying that all fluctuations happened 12-months sooner than they did in reality. Hence, finding similar estimates to our main results presented in Table 2 would lend significant doubt to the validity of our current findings: it would suggest that fluctuations in the DJIA that occur in the future had impacts on child health in the past. As can be seen in Table 4, estimates from this falsification analysis show no relationship, helping alleviate concerns that our findings are spurious.

Next, it is imperative for our identification to separately identify the behavioral response of the stock market fluctuations from business cycle fluctuations. To this end, we test the sensitivity of our results to excluding the business cycle controls. The results are very similar, demonstrating that the conditional stock market effects are relatively independent of the business cycle (see Appendix Table 1 for more details).

Lastly, we investigate the sensitivity of some of our empirical choices. We have been using a linear specification for our baseline estimates, so we re-estimate our primary results using a probit (when appropriate). The results are robust to the specification selected (see Appendix Table 2). Also, given that stock market fluctuations occur at the national level, it may not be appropriate to assume that errors are independent across year and month. There is no meaningful change in

\footnotetext{
${ }^{9}$ We experimented with different combinations of introducing these covariates, but coefficient estimates remain markedly similar.

${ }^{10}$ Since our main specification is lagged six months from the month of interview to match the retrospective nature of the health questions, this means the falsification test is a 6 months forward from the month of interview.
} 
statistical significance or interpretation when standard errors are clustered at the year level. See Appendix Table 3 for more details.

\section{c. Sub-Group Analysis}

In this section, we investigate whether there is heterogeneity in response to changes in the stock market across different sub-groups. Understanding which specific groups are responding can provide insight on the underlying mechanism impacting behavior. Tables $5-7$ report sample subgroup results that vary by child's age, sex, and mother's education.

We first investigate heterogeneity depending on child age, as shown in Table 5. Results indicate that estimates are relatively consistent across age group, but, generally speaking, the impacts are larger and/or more precisely measured for younger children. This is consistent with earlier work that suggests that early life is a time when children are more susceptible to shocks to parent's socio-economic status and mental health (Currie, 2009).

Next we estimate separate models for male and female children, shown in Table 6. Results indicate similar impacts of stock markets declines on hospitalization and emotional difficulties for both male and female children. However, estimates also suggest that the impact of market fluctuations on sick days from school and overall health status seem to be driven by a larger response among females. In particular, the estimated effects on the health status of females are twice as large as observed among males, and almost four times larger regarding sick days from school. Overall, the general qualitative story is the same for both genders, but the impacts of market declines on child health seem to be somewhat larger for girls.

Lastly, Table 7 stratifies our results by mother's educational attainment. Specifically, we split the sample by children whose mother dropped out of high school (very low human capital) 
versus a college degree (high human capital). Results presented in Table 7 show that children whose mother was a high school dropout have a higher propensity for increased sick days from school and decreased emotional health during an economic decline. On the other hand, hospitalization effects were focused on high education groups. This potentially suggests different mechanisms between the different outcomes. Children from Low SES backgrounds may be more vulnerable to the general stress and uncertainty induced by a market crash even though those families are less likely to hold stock. On the other hand, high socio-economic status families may have the ability to respond to a health shock generated by a stock market crash by increasing medical utilization. We investigate this more in section $\mathrm{d}$. below, where we use data from the Survey of Consumer Finance (SCF) to predict the likelihood of a family holding stock.

In general, we find larger impacts among younger, female children. But, we also note, general effects are observed in most sub-groups to some extent, and in some cases larger effects are observed among children of low-education mothers, which is a group that one would not expect to be explicitly impacted by stock market fluctuations as they are less likely to own stock. While we take this issue up in more detail in the next section, it does speak to the hypothesis that stock market fluctuations may impact overall population health and behavior by increasing stress and providing information about future outcomes, which could impact personal discount rates (Becker, 2007).

\section{d. Extension: Analysis of Stock-holders versus non-stock holders}

If stock market fluctuations are impacting child health, an open question is what are the driving forces? In particular, are the impacts of stock market fluctuation on health the result of a shift in behavior caused by a change in assessment of national wealth and stability by the general 
population, regardless of direct stock market ownership? Alternatively, are the measured impacts from income effects isolated to the segment of the population who own stock specifically?

In order to attempt to provide insight into these questions, we calculated predicted probabilities of holding stock and expected portfolio values conditional on holding stock for NHIS respondents using the 2007 cross-section Survey of Consumer Finances (SCF) (Board of Governors of the Federal Reserve System). We regressed a dichotomous measure of any stock holdings ${ }^{11}$ (probit model) on SCF variables that could be mapped to the NHIS analysis control variables. These include measures of sex, age, education, race/ethnicity, marital status, employment status, and income. For each NHIS child between 2004 and 2012 we predicted whether their parents owned stock and the natural log of the portfolio value conditional on positive predicted stock holdings using the estimated model. The 2007 SCF model was assumed to be representative of stock holdings among the population prior to the 2008-2009 stock market crash.

Results from an analysis of whether the health of children of stock holders was more likely to be impacted by fluctuations in the stock market are reported in Table 8 . Specifically, Table 8 stratifies the sample by predicted stock ownership. There are some differences between the groups in the impact of fluctuations in the DJIA on our child health measures. In particular, the magnitude of the effects on hospitalization and sick days is meaningfully larger for children of (predicted) stock owning families, while the opposite is true for reported health and reported emotional health. We take this as suggestive evidence that the impact of declines in the DJIA on children of stock holders impacts tangible outcomes more. However, the general emotional distress associated with declines in the stock market may impact children of non-holders more through stress-related

\footnotetext{
${ }^{11}$ Reported as stocks or stock mutual funds.
} 
channels. These results demonstrate that responses to stock market fluctuations impacted both stockholders and non-stockholders (although for different reasons), and helps support the notion that as a leading indicator of economic activity the stock market has effects that are widely shared among the population.

\section{Discussion and Conclusion}

The stock market crash of 2008 caused a severe impact to households across the United States. The impacts of a stock market crash on family welfare and behavior have been identified for life wellbeing, psychological stress, and adult health behaviors. We have attempted to add to this literature by documenting impacts of stock market fluctuations on a range of child outcomes; including effects on both mental and physical health. Specifically, we show the negative effect of a stock market crash on hospitalizations, child reported excellent health status, sick days from school, and severe emotional difficulties. A graphic analysis shows that our results are not driven by a spurious pre-trend of declining child health before the market crash. Similarly, our regression results are robust to a range of specifications and robustness tests.

One way to get a sense of the economic significance of our findings is to examine the monetary value of one of our most robust and easily quantifiable outcome variables: hospitalizations. We estimate that a percent decrease in the stock market increases the likelihood of a child being hospitalized by 0.49 percentage points. On average, the dollar value cost for a childhood hospital visit is $\$ 8,200$ per stay (AHRQ, 2013). This suggests that a one percent decrease in the stock market increased the expenditures on hospitalizations per child by $\$ 401$. In the context of the financial crisis, the stock market dropped by 50\%; representing a loss of $\$ 20,050$ dollars from hospitalizations per child. While the other outcomes are harder to quantify, these findings alone suggest non-trivial effects. 
We have additionally explored a number of mechanisms by which the market crash could have influenced outcomes. Wide spread effects across subgroups suggests that more than just stock holders were impacted. This lends credence to the interpretation of the stock market crash as affecting behavior, and potentially emotional stress, through changes in information about the future health of the economy.

\section{References}

Almond, Douglas, \& Currie, Janet. (n.d.). Human Capital Development Before Age 5. In Handbook of Labor Economics (Vol. 4, pp. 773-1823).

Arkes, J. (2007). Does the economy affect teenage substance use? Health Economics, 16(1), 1936. http://doi.org/10.1002/hec.1132

Arkes, J., \& Klerman, J. A. (2009). Understanding the Link between the Economy and Teenage Sexual Behavior and Fertility Outcomes. Journal of Population Economics, 22(3), 517-536.

Becker GS. Health as human capital: synthesis and extensions. Oxford Economic Papers 2007; $59379-410$.

Board of Governors of the Federal Reserve System. 2013. Survey of Consumer Finances. 2013. Available at: http://www.federalreserve.gov/econresdata/scf/scf_2007.htm.

Charles KK, DeCicca P. Local labor market fluctuations and health: Is there a connection and for whom? Journal of Health Economics 2008; 27; 1532-1550.

Classen TJ, Dunn RA. The effect of job loss and unemployment duration on suicide risk in the United States: a new look using mass-layoffs and unemployment duration. Health Economics 2012; 21; 338-350.

Cotti C, Dunn RA, Tefft N. The Dow is Killing Me: Risky Health Behaviors and the Stock Market. Health Economics, July 2015, Vol. 24, No. 7: 803-821.

Cotti C, Tefft N. Decomposing the Relationship between Macroeconomic Conditions and Fatal Car Crashes during the Great Recession: Alcohol- and Non-Alcohol-Related Accidents. The B.E. Journal of Economic Analysis \& Policy 2011; 11.

Currie, J. (2009). Healthy, Wealthy, and Wise: Socioeconomic Status, Poor Health in Childhood, and Human Capital Development. Journal of Economic Literature, 47(1), 87-122 
Deaton AS. The financial crisis and the well-being of Americans: 2011 OEP Hicks Lecture. Oxford Economic Papers 2011b.

Dehejia, R., \& Lleras-Muney, A. (2004). Booms, Busts, and Babies' Health. The Quarterly Journal of Economics, 119(3), 1091-1130. http://doi.org/10.1162/0033553041502216

Engelberg J, Parsons C. Can the stock market make you sick? Working Paper, San Diego, CA; 2013.

Ettner SL. Measuring the human cost of a weak economy: Does unemployment lead to alcohol abuse? Social Science \& Medicine 1997; 44; 251-260.

Evans WN, Moore TJ. Liquidity, Economic Activity, and Mortality. Review of Economics and Statistics 2012; 94; 400-418. http://dx.doi.org/10.1162/REST_a_00184.

Freeman DG. A note on 'Economic conditions and alcohol problems'. Journal of Health Economics 1999; 18; 661-670.

Gallup Inc. 2011. In U.S., 54\% Have Stock Market Investments, Lowest Since 1999. 2011. Available at: http://www.gallup.com/poll/147206/stock-market-investments-lowest1999.aspx.

Klein T. 1986. A METHOD FOR ESTIMATING POSTERIOR BAC DISTRIBUTIONS FOR PERSONS INVOLVED IN FATAL TRAFFIC ACCIDENTS. 1986. Available at: http://trid.trb.org/view .aspx?id=310222.

Krüger NA, Svensson M. Good times are drinking times: empirical evidence on business cycles and alcohol sales in Sweden 1861-2000. Applied Economics Letters 2008; 17; 543-546.

Ma W, Chen H, Jiang L, Song G, Kan H. Stock volatility as a risk factor for coronary heart disease death. European Heart Journal 2011; 32 1006-1011.

McInerney M, Mellor J, Nicholas LH. Recession Depression: Physical and Mental Health Effects of the 2008 Stock Market Crash (College of William and Mary Working Paper). 2012.

Neumayer E. Recessions lower (some) mortality rates:: evidence from Germany. Social Science \&amp; Medicine 2004; 58; 1037-1047.

Page, Marianne, Jessamyn Schaller, \& David Simon. (n.d.). The Effects of Aggregate and Gender-Specific Labor Demand Shocks on Children's Health. University of Connecticut Working Paper.

Ruhm CJ. Economic conditions and alcohol problems. Journal of Health Economics 1995; 14; 583-603. http://www.sciencedirect.com/science/article/pii/0167629695000240. 
Are Recessions Good for Your Health? The Quarterly Journal of Economics 2000; 115; $617-650$.

—. Healthy living in hard times. Journal of Health Economics 2005; 24; 341-363.

Ruhm CJ, Black WE. Does drinking really decrease in bad times? Journal of Health Economics 2002; 21; 659-678. http://www.sciencedirect.com/science/article/pii/S0167629602000334.

Schaller, Jessamyn. Booms, Busts, and Fertility: Testing the Becker Model Using GenderSpecific Labor Demand,". Forthcoming, Journal of Human Resources.

Schwandt, H. (2014). Wealth Shocks and Health Outcomes: Evidence from Stock Market Fluctuations (SSRN Scholarly Paper No. ID 2465333). Rochester, NY: Social Science Research Network. Retrieved from http://papers.ssrn.com/abstract=2465333.

Simon, D. E. (2013). Does Early Life Exposure to Cigarette Smoke Permanently Harm Childhood Health? Evidence from Cigarette Tax Hikes (Working paper No. 2013-21). University of Connecticut, Department of Economics. Retrieved from http://econpapers.repec.org/paper/uctuconnp/2013-21.htm

Stevens, A. H., Miller, D. L., Page, M. E., \& Filipski, M. (2011). The Best of Times, the Worst of Times: Understanding Pro-cyclical Mortality (Working Paper No. 17657). National Bureau of Economic Research. Retrieved from http://www.nber.org/papers/w17657

Tapia Granados J. Recessions and Mortality in Spain, 1980-1997. European Journal of Population / Revue Européenne De Démographie 2005; 21; 393-422 LA - English. 


\section{Figures}

Figure 1: Fluctuations in the Dow Jones and the Unemployment Rate by Quarter 2004-2012

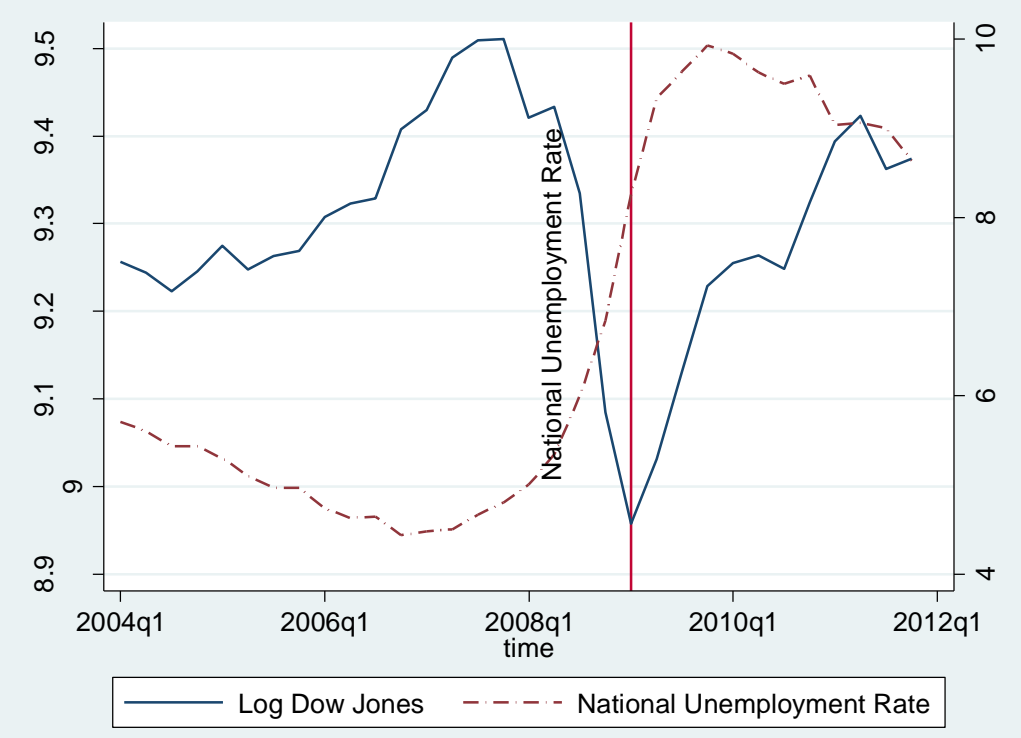

Notes: Data on the monthly closing value of the Dow Jones is from the St. Loui's FRED Economic Data web site. Data on the monthly national unemployment rate is from the bureau of labor statistics. The vertical line in the $3^{\text {rd }}$ quarter of 2008 represents the trough of the stock market decline. The correlation coefficient between the log monthly closing Dow Jones and the monthly unemployment rate is -0.21 .

Figure 2: Fluctuations in the 6 Month Lagged Dow Jones and Reported Health of Child 


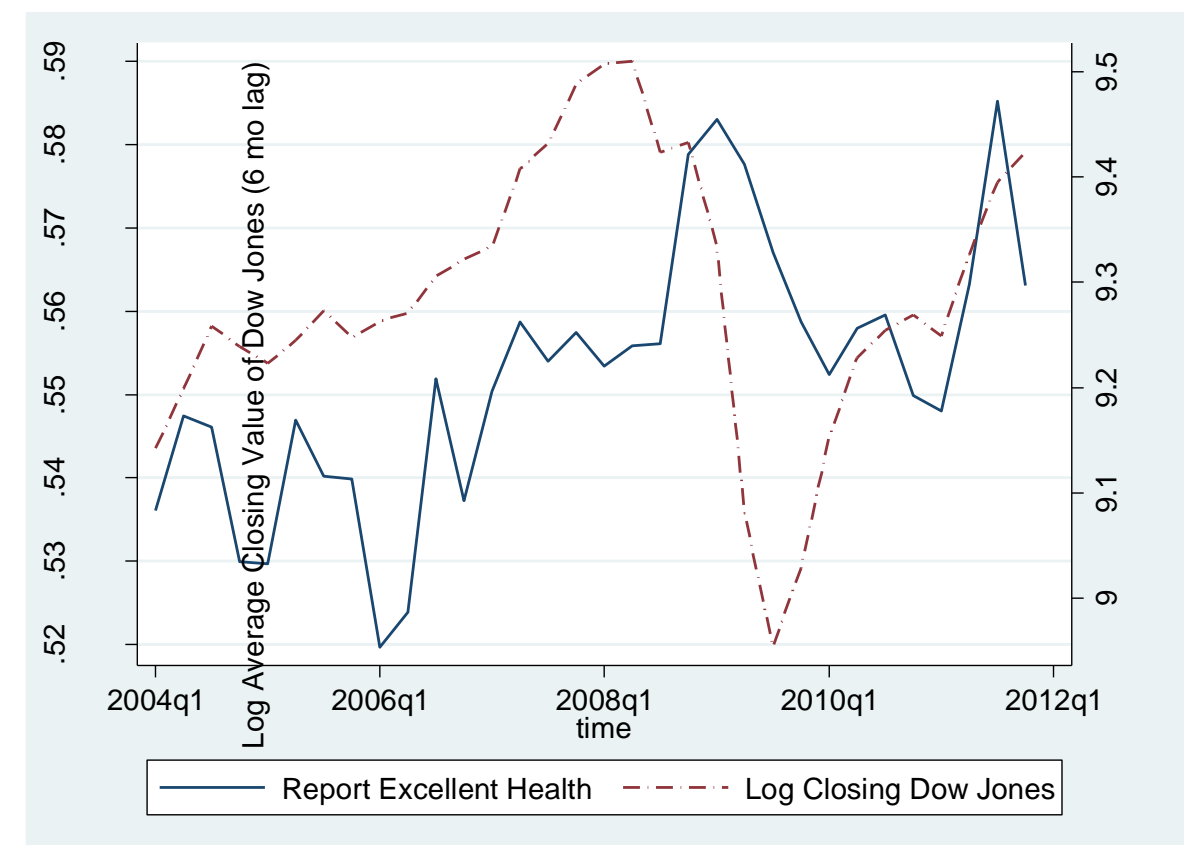

Notes: The above graph shows the impact of the 6 month lagged Dow Jones on a parent reporting excellent health status for their child. Monthly Dow jones data averaged into quarterly bins comes from the St. Louis Fed's FRED Economic Data web site. Mean reported excellent health averaged into quarterly bins comes from the 2004-2012 waves of the National Health Interview Survey data.

Figure 3. Fluctuations in the 6 Month Lagged Dow Jones and Child Health Outcomes

\section{Panel A: Excellent Health}

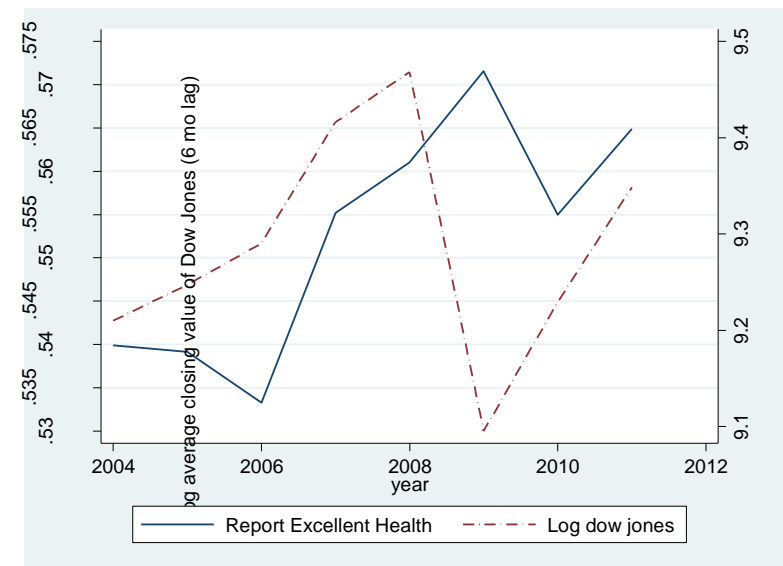

Panel B: Sick Days from School

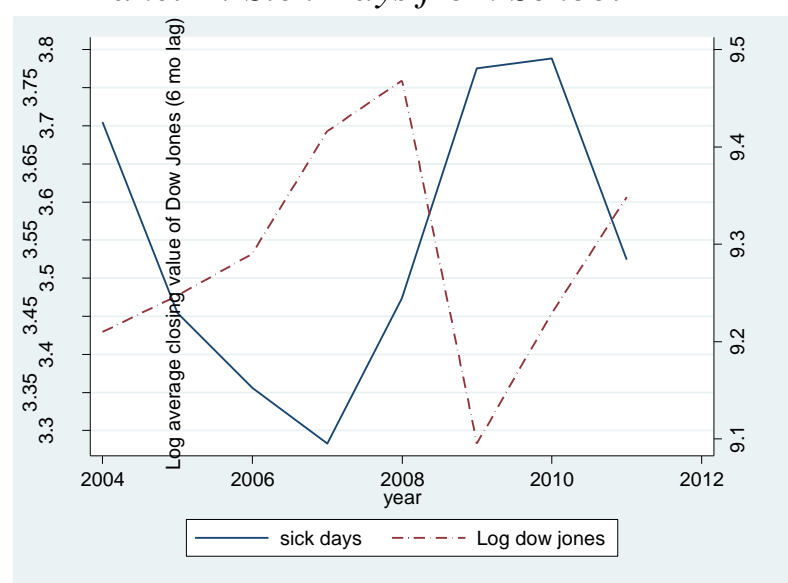


Panel C: Hospitalizations

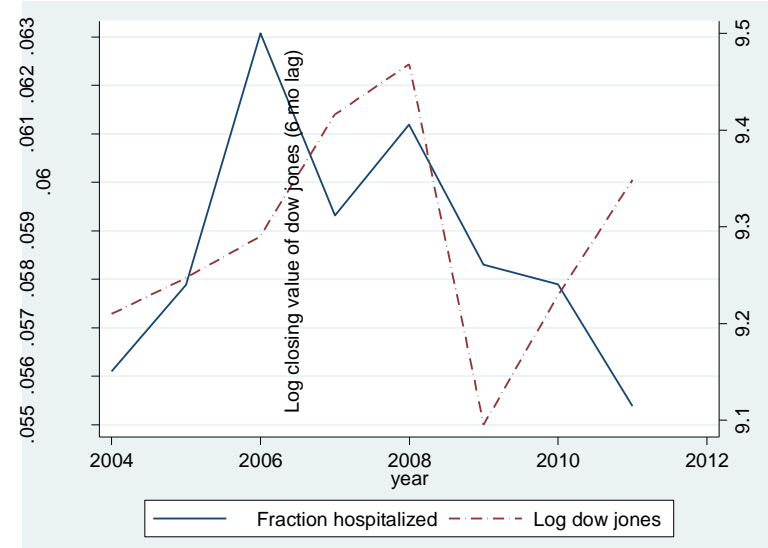

Panel D: Reported Emotional Difficulties

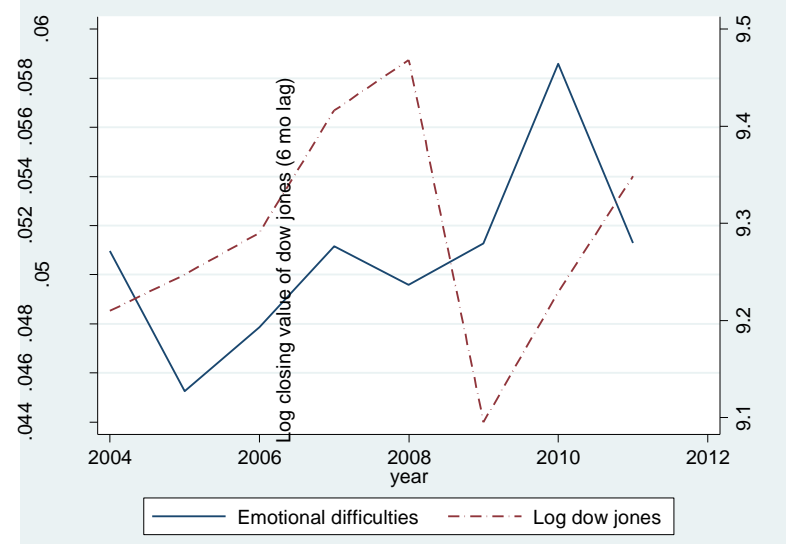

Notes: The above graph shows how the 6 month lagged Dow Jones changes with the given health outcome. Monthly Dow jones data averaged into yearly bins comes from the St. Louis Fed's FRED Economic Data web site. Mean health outcomes averaged into quarterly bins comes from the 2004-2012 waves of the National Health Interview Survey data.

\section{Tables}


Table 1: Summary Statistics

\begin{tabular}{|c|c|c|c|c|}
\hline \multicolumn{2}{|c|}{ Demographic Covariates } & \multicolumn{3}{|c|}{ Outcome Variables } \\
\hline & mean/sd & & Mean/sd & $\mathrm{N}$ \\
\hline \multirow[t]{2}{*}{ white } & 0.71 & hospitalizaiton in past & 0.06 & 202445 \\
\hline & $(0.46)$ & 12 months & $(0.23)$ & \\
\hline \multirow[t]{2}{*}{ black } & 0.15 & & & \\
\hline & $(0.36)$ & Excellent Health & 0.55 & 202718 \\
\hline \multirow[t]{2}{*}{ other } & 0.15 & & $(0.50)$ & \\
\hline & $(0.35)$ & & & \\
\hline \multirow[t]{2}{*}{ Mother dropout } & 0.16 & Sick days from school & 3.49 & 64710 \\
\hline & $(0.36)$ & in past 12 months & (6.46) & \\
\hline \multirow[t]{2}{*}{ Mother highschool } & 0.24 & & & \\
\hline & $(0.42)$ & Definite emotional & 0.05 & 70299 \\
\hline \multirow[t]{2}{*}{ Mother some college } & 0.31 & difficulties in 6 months & $(0.22)$ & \\
\hline & $(0.46)$ & & & \\
\hline \multirow[t]{2}{*}{ college } & 0.27 & & & \\
\hline & $(0.45)$ & & & \\
\hline \multirow[t]{2}{*}{ black } & 0.15 & & & \\
\hline & $(0.36)$ & & & \\
\hline \multirow[t]{2}{*}{ white } & 0.71 & & & \\
\hline & $(0.46)$ & & & \\
\hline \multirow[t]{2}{*}{ other race } & 0.15 & & & \\
\hline & $(0.35)$ & & & \\
\hline \multirow[t]{2}{*}{ Child's age } & 8.41 & & & \\
\hline & $(5.20)$ & & & \\
\hline
\end{tabular}

Notes: The dataset is the 2004 to 2012 waves of the National Health Interview Survey (NHIS). We include all available observations on children ages $0-17$. Depending on the outcome variable looked at, sample sizes change due to missing observations. Information on hospitalizations and excellent health are contained in the NHIS person core questionnaire which asks questions of all children in the household. Sick days from school and emotional difficulties are asked about in the NHIS sample child questionnaire which only interviews one child per household. 
Table 2. The Impact of The 2008-2009 Stock Market Fluctuations in the DJIA on Children's Health Outcomes

\begin{tabular}{l|c|c|c|c}
\hline & Hospitalization & School Sick Days & Health Status: Excellent & $\begin{array}{c}\text { Emotional } \\
\text { Difficulties }\end{array}$ \\
\hline : DJIA Index & & & & \\
\hline Ln average daily close, DJIA & $-0.049^{* * *}$ & -0.736 & $0.084^{*}$ & $-0.048^{*}$ \\
Unemployment rate & $(0.014)$ & $(0.738)$ & $(0.039)$ & $(0.024)$ \\
& $-0.005^{* *}$ & 0.025 & 0.0004 & -0.004 \\
$N$ & $(0.002)$ & $(0.113)$ & $(0.005)$ & $(0.003)$ \\
Mean of Dependent Variable: & 171,465 & 56,844 & 171,479 & 61,657 \\
\hline
\end{tabular}

Notes: All models include controls for race, gender, child's age, mother's age, mother's education, mother's marital status, household income, employment status, insurance status, and indicators for year and month. Robust standard errors clustered by year-month are in parentheses. $* * * \mathrm{p}<0.01, * * \mathrm{p}<0.05, * \mathrm{p}<0.1$ 
Table 3. The impact of the 2008-2009 stock market fluctuations in the DJIA on measures of children's health outcomes, robustness across various specifications.

\begin{tabular}{|c|c|c|c|c|c|c|c|c|c|c|c|}
\hline \multicolumn{6}{|c|}{ Panel A: Hospitalization } & \multicolumn{6}{|c|}{ Panel B: Health Status Excellent } \\
\hline Log Dow Jones & $\begin{array}{l}-0.048 * * \\
(0.011)\end{array}$ & $\begin{array}{l}-0.048 * * * \\
(0.014)\end{array}$ & $\begin{array}{l}-0.049 * * * \\
(0.014)\end{array}$ & $\begin{array}{l}-0.049 * * * \\
(0.014)\end{array}$ & $\begin{array}{l}-0.049 * * * \\
(0.014)\end{array}$ & Log Dow Jones & $\begin{array}{l}0.084 * * * \\
(0.012)\end{array}$ & $\begin{array}{l}0.084 * * \\
(0.039)\end{array}$ & $\begin{array}{l}0.084 * * \\
(0.039)\end{array}$ & $\begin{array}{l}0.084 * * \\
(0.039)\end{array}$ & $\begin{array}{l}0.084 * * \\
(0.038)\end{array}$ \\
\hline$N$ & 171,465 & 171,465 & 171,465 & 171,465 & 171,465 & $N$ & 171,479 & 171,479 & 171,479 & 171,479 & 171,479 \\
\hline $\begin{array}{l}\text { Includes Insurance } \\
\text { Status } \\
\text { Includes }\end{array}$ & No & Yes & Yes & Yes & Yes & $\begin{array}{l}\text { Includes Insurance } \\
\text { Status } \\
\text { Includes }\end{array}$ & No & Yes & Yes & Yes & Yes \\
\hline $\begin{array}{l}\text { Employment Status } \\
\text { Includes Income }\end{array}$ & No & No & Yes & Yes & Yes & $\begin{array}{l}\text { Employment Status } \\
\text { Includes Income }\end{array}$ & No & No & Yes & Yes & Yes \\
\hline $\begin{array}{l}\text { Measures } \\
\text { Includes Linear }\end{array}$ & No & No & No & Yes & Yes & $\begin{array}{l}\text { Measures } \\
\text { Includes Linear }\end{array}$ & No & No & No & Yes & Yes \\
\hline Time Trends & No & No & No & No & Yes & Time Trends & No & No & No & No & Yes \\
\hline \multicolumn{6}{|c|}{ Panel C: School Sick Days } & \multicolumn{6}{|c|}{ Panel D: Emotional Difficulties } \\
\hline Log Dow Jones & $\begin{array}{l}-0.646 \\
(0.769)\end{array}$ & $\begin{array}{l}-0.642 \\
(0.768)\end{array}$ & $\begin{array}{l}-0.703 \\
(0.769)\end{array}$ & $\begin{array}{l}-0.736 \\
(0.770)\end{array}$ & $\begin{array}{l}-0.736 \\
(0.770)\end{array}$ & Log Dow Jones & $\begin{array}{l}-0.044 * \\
(0.024)\end{array}$ & $\begin{array}{l}-0.044 * \\
(0.024)\end{array}$ & $\begin{array}{l}-0.047 * \\
(0.024)\end{array}$ & $\begin{array}{l}-0.048 * \\
(0.024)\end{array}$ & $\begin{array}{l}-0.048 * \\
(0.024)\end{array}$ \\
\hline$N$ & 56,844 & 56,844 & 56,844 & 56,844 & 56,844 & $N$ & 61,657 & 61,657 & 61,657 & 61,657 & 61,657 \\
\hline $\begin{array}{l}\text { Includes Insurance } \\
\text { Status } \\
\text { Includes }\end{array}$ & No & Yes & Yes & Yes & Yes & $\begin{array}{l}\text { Includes Insurance } \\
\text { Status } \\
\text { Includes }\end{array}$ & No & Yes & Yes & Yes & Yes \\
\hline $\begin{array}{l}\text { Employment Status } \\
\text { Includes Income }\end{array}$ & No & No & Yes & Yes & Yes & $\begin{array}{l}\text { Employment Status } \\
\text { Includes Income }\end{array}$ & No & No & Yes & Yes & Yes \\
\hline $\begin{array}{l}\text { Measures } \\
\text { Includes Linear }\end{array}$ & No & No & No & Yes & Yes & $\begin{array}{l}\text { Measures } \\
\text { Includes Linear }\end{array}$ & No & No & No & Yes & Yes \\
\hline Time Trends & No & No & No & No & Yes & Time Trends & No & No & No & No & Yes \\
\hline
\end{tabular}

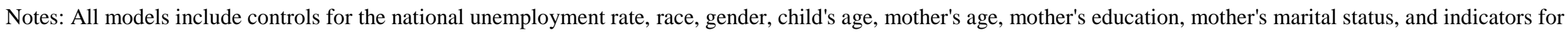
year and month. Robust standard errors clustered by year-month are in parentheses.

$* * * \mathrm{p}<0.01, * * \mathrm{p}<0.05, * \mathrm{p}<0.1$ 
Table 4: Falsification Test: 12 Month Leads

\begin{tabular}{|c|c|c|c|c|}
\hline & Hospitalization & $\begin{array}{l}\text { School Sick } \\
\text { Days }\end{array}$ & $\begin{array}{l}\text { Health Status: } \\
\text { Excellent }\end{array}$ & $\begin{array}{l}\text { Emotional } \\
\text { Difficulties }\end{array}$ \\
\hline $\begin{array}{l}12 \text { month lead Ln average } \\
\text { daily }\end{array}$ & -0.004 & 0.040 & 0.024 & -0.020 \\
\hline Close, DJIA & $(0.008)$ & $(0.376)$ & $(0.028)$ & $(0.014)$ \\
\hline$N$ & 159,384 & 52,798 & 159,401 & 57,300 \\
\hline
\end{tabular}

Notes: All models include controls for race, gender, child's age, mother's age, mother's education, mother's marital status, household income, employment status, insurance status, and indicators for year and month. Robust standard errors clustered by year-month are in parentheses.

$* * * \mathrm{p}<0.01, * * \mathrm{p}<0.05, * \mathrm{p}<0.1$

Table 5. The Impact of Stock Market Fluctuations on Child Health by Child Age Groups

\begin{tabular}{c|ccc}
\hline & Less than 5 & Age 5-11 & Age 12-17 \\
Ln average daily & Ln average daily close, & Ln average daily close, \\
close, DJIA & DJIA & DJIA \\
$N$ & $-0.11^{* *}$ & $-0.02^{*}$ & -0.02 \\
Mean of Dependent Variable: & $(0.04)$ & $(0.01)$ & $(0.02)$ \\
School Sick Days & 48,179 & 67,640 & 55,646 \\
$N$ & 0.16 & 0.02 & 0.02 \\
Mean of Dependent Variable: & & -0.66 & -0.73 \\
& & $(0.83)$ & $(1.12)$ \\
Health Status: Excellent & & 28,926 & 27,918 \\
& & 3.14 & 3.66 \\
$N$ & 0.02 & & 0.08 \\
Mean of Dependent Variable: & $(0.04)$ & $0.14 * *$ & $(0.05)$ \\
& 48,185 & $(0.05)$ & 55,647 \\
Emotional Difficulties & 0.59 & 67,647 & 0.53 \\
& & & $-0.06^{*}$ \\
Mean of Dependent Variable: & & 0.55 & $(0.03)$ \\
& & -0.04 & 27,969
\end{tabular}

Notes: All models include controls for race, gender, child's age, mother's age, mother's education, mother's marital status, household income, employment status, insurance status, and indicators for year and month. Robust standard errors clustered by year-month are in parentheses.

$* * * \mathrm{p}<0.01, * * \mathrm{p}<0.05, * \mathrm{p}<0.1$ 
Table 6. The Impact of Stock Market Fluctuations on Child Health by Child Gender

\begin{tabular}{c|cc}
\hline & Male & Female \\
& Ln average daily close, & Ln average daily close, \\
Hospitalization & DJIA & DJIA \\
$N$ & $-0.05^{* *}$ & $-0.04^{* *}$ \\
Mean of Dependent Variable: & $(0.02)$ & $(0.02)$ \\
Coefficient / Mean: & 87,296 & 84,169 \\
& 0.06 & 0.06 \\
School Sick Days & $-93.18 \%$ & $-75.22 \%$ \\
$N$ & & \\
Mean of Dependent Variable: & -0.3 & -1.14 \\
Coefficient / Mean: & $(0.94)$ & $(1.22)$ \\
& 29,054 & 27,790 \\
Health Status: Excellent & 3.26 & 3.5 \\
& $-9.2 \%$ & $-32.56 \%$ \\
$N$ & & \\
Mean of Dependent Variable: & 0.054 & $0.115^{* *}$ \\
Coefficient / Mean: & $(0.042)$ & $(0.045)$ \\
& & \\
Emotional Difficulties & $0.54,299$ & 84,180 \\
$N$ & $9.87 \%$ & 0.563 \\
Mean of Dependent Variable: & & $20.43 \%$ \\
Coefficient / Mean: & -0.05 & $-0.045^{*}$ \\
\hline
\end{tabular}

Notes: All models include controls for race, gender, child's age, mother's age, mother's education, mother's marital status, household income, employment status, insurance status, and indicators for year and month. Robust standard errors clustered by year-month are in parentheses.

$* * * \mathrm{p}<0.01, * * \mathrm{p}<0.05, * \mathrm{p}<0.1$ 
Table 7. The Impact of Stock Market Fluctuations on Child Health by Mother's Education

\begin{tabular}{c|cc}
\hline & $\begin{array}{c}\text { High School Dropout } \\
\text { Ln average daily close, }\end{array}$ & $\begin{array}{c}\text { College } \\
\text { DJIA }\end{array}$ \\
Hospitalization & -0.007 & DJIA \\
$N$ & $(0.023)$ & $-0.07 * *$ \\
Mean of Dependent Variable: & 36,495 & $(0.03)$ \\
Coefficient / Mean: & 0.06 & 40,669 \\
School Sick Days & $-12.06 \%$ & 0.06 \\
& & $-124.2 \%$ \\
$N$ & -2.15 & -0.12 \\
Mean of Dependent Variable: & $(1.63)$ & $(0.83)$ \\
Coefficient / Mean: & 10,355 & 14,194 \\
& 3.32 & 2.88 \\
Health Status: Excellent & $-64.87 \%$ & $-4.13 \%$ \\
& & \\
$N$ & -0.03 & -0.001 \\
Mean of Dependent Variable: & $(0.11)$ & $(0.08)$ \\
Coefficient / Mean: & 36,489 & 40,665 \\
Emotional Difficulties & 0.42 & 0.69 \\
Mean of Dependent Variable: & $-7.67 \%$ & $-11.39 \%$ \\
Coefficient / Mean: & $-0.12 * *$ & 0.003 \\
& $(0.05)$ & $(0.05)$ \\
& 11,343 & 15,386 \\
\hline
\end{tabular}

Notes: All models include controls for race, gender, child's age, mother's age, mother's education, mother's marital status, household income, employment status, insurance status, and indicators for year and month. Robust standard errors clustered by year-month are in parentheses.

$* * * \mathrm{p}<0.01, * * \mathrm{p}<0.05, * \mathrm{p}<0.1$ 
Table 8: The Impact of Stock Market Fluctuations on Child Health Analysis Using Predicted Probability of Stock Ownership

\begin{tabular}{lcccc}
\hline & Hospitalization & School Sick Days & Health Status: Excellent & $\begin{array}{c}\text { Emotional } \\
\text { Difficulties }\end{array}$ \\
\hline $\begin{array}{l}\text { Panel A: Predicted Stock } \\
\text { Ownership- Yes }\end{array}$ & & & & \\
\cline { 1 - 2 } Ln average daily close, DJIA & $-0.11^{* *}$ & $-3.18^{* *}$ & 0.06 & 0.04 \\
& $(0.04)$ & $(1.17)$ & $(0.12)$ & $(0.06)$ \\
$N$ & 15,686 & 5,477 & 15,683 & 5,904 \\
Mean of Dependent Variable: & 0.15 & 0.02 & 0.03 & 0.02 \\
\hline $\begin{array}{l}\text { Panel B: Predicted Stock } \\
\text { Ownership-No }\end{array}$ & & & & $-0.06^{* *}$ \\
Ln average daily close, DJIA & $-0.04^{* *}$ & -0.43 & $0.09^{* *}$ & $(0.03)$ \\
& $(0.01)$ & $(0.87)$ & $(0.04)$ & 55,753 \\
$N$ & 155,779 & 51,367 & 155,796 & 0.02 \\
Mean of Dependent Variable: & 0.13 & 0.03 & 0.05 & \\
\hline
\end{tabular}

Notes: All models include controls for race, gender, child's age, mother's age, mother's education, mother's marital status, household income, employment status, insurance status, and indicators for year and month. Robust standard errors clustered by household are in parentheses.

$* * * \mathrm{p}<0.01, * * \mathrm{p}<0.05, * \mathrm{p}<0.1$ 


\section{Appendix}

Appendix Figure A-1. Residuals of the 6 Month Lagged Dow Jones and Residuals of Child Health Outcomes

Panel A: Excellent Health

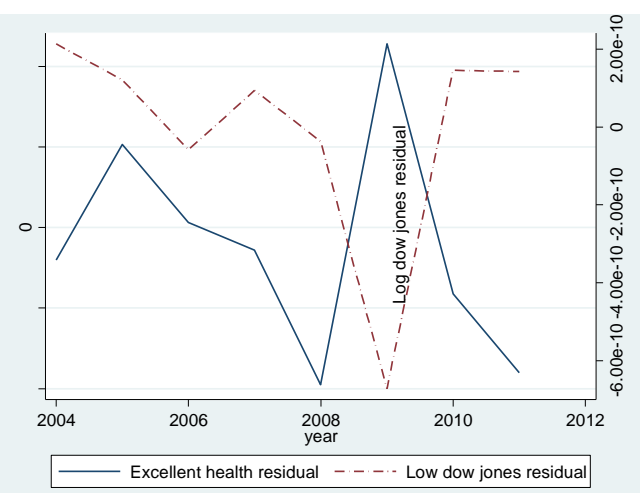

Panel C: Hospitalizations

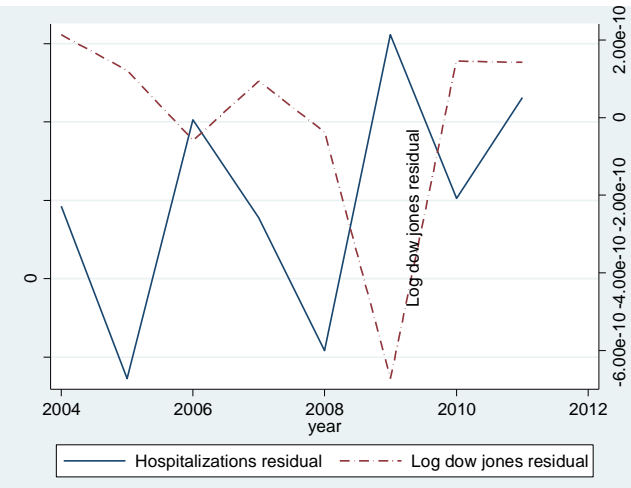

Panel B: Sick Days from School

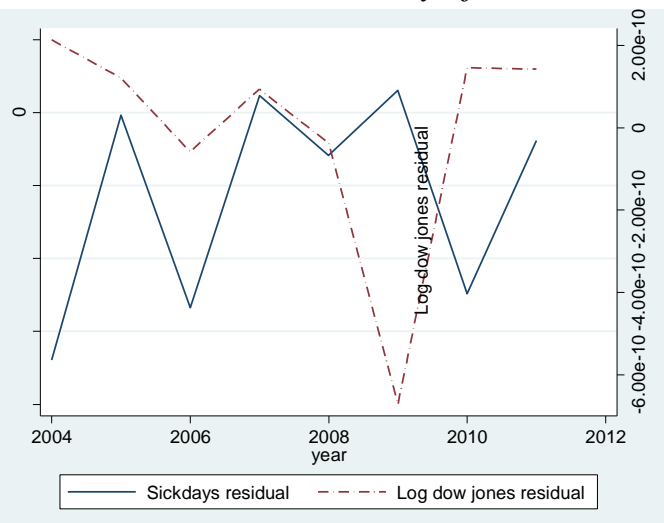

Panel D: Reported Emotional Difficulties

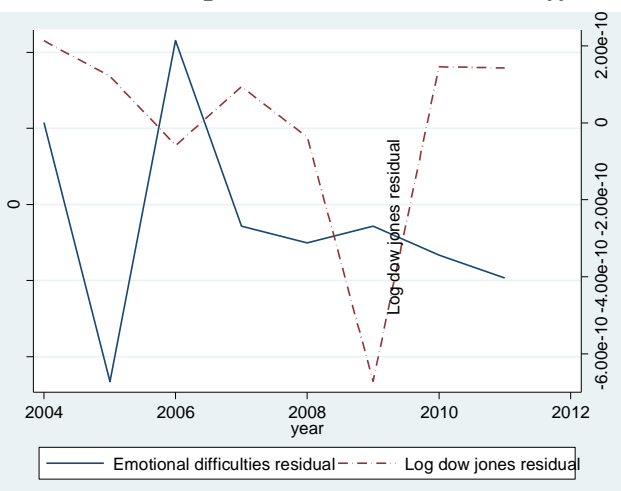

Notes: The above figures graph the predicted residuals of the given child health outcome (from a regression using the unemployment rate, year fixed effects, and month fixed effects) next to the residuals of the log Dow Jones. Monthly Dow Jones data averaged into quarterly bins comes from the St. Louis Fed's FRED Economic Data web site. Mean reported health averaged into yearly bins comes from the 2004-2012 waves of the National Health Interview Survey data. 
Appendix Table A-1: Business Cycle Controls Excluded.

\begin{tabular}{l|c|c|c|c}
\hline & Hospitalization & $\begin{array}{c}\text { School Sick } \\
\text { Days }\end{array}$ & $\begin{array}{c}\text { Health Status: } \\
\text { Excellent }\end{array}$ & $\begin{array}{c}\text { Emotional } \\
\text { Difficulties }\end{array}$ \\
\hline Panel A: DJIA Index & & & & \\
\hline Ln average daily close, DJIA & $-0.025^{* *}$ & $-0.870^{*}$ & $0.082^{* *}$ & -0.027 \\
& $(0.010)$ & $(0.515)$ & $(0.034)$ & $(0.019)$ \\
$N$ & 171,465 & 56,844 & 171,479 & 61,657 \\
Mean of Dependent Variable: & 0.0570 & 3.49 & 0.555 & 0.051 \\
\hline
\end{tabular}

Notes: All models include controls for race, gender, child's age, mother's age, mother's education, mother's marital status, household income, employment status, insurance status, and indicators for year and month.

Robust standard errors clustered by household are in parentheses.

$* * * \mathrm{p}<0.01, * * \mathrm{p}<0.05, * \mathrm{p}<0.1$

Appendix Table A-2: Probit Models.

\begin{tabular}{l|c|c|c|c}
\hline & Hospitalization & $\begin{array}{c}\text { School Sick } \\
\text { Days }\end{array}$ & $\begin{array}{c}\text { Health Status: } \\
\text { Excellent }\end{array}$ & $\begin{array}{c}\text { Emotional } \\
\text { Difficulties }\end{array}$ \\
\hline Panel A: DJIA Index & & & & \\
\hline Ln average daily close, DJIA & $-0.045^{* * *}$ & NA & $(0.044)$ & $-0.046^{*}$ \\
& $(0.014)$ & & & $(0.26)$ \\
$N$ & 171,465 & & 171,479 & 61,657 \\
Mean of Dependent Variable: & 0.0570 & & 0.555 & 0.051 \\
\hline
\end{tabular}

Notes: All models include controls for race, gender, child's age, mother's age, mother's education, mother's marital status, household income, employment status, insurance status, and indicators for year and month.

Robust standard errors clustered by household are in parentheses.

$* * * \mathrm{p}<0.01, * * \mathrm{p}<0.05, * \mathrm{p}<0.1$

Appendix Table A-3: Standard Errors Clustered at the Year Level.

\begin{tabular}{l|c|c|c|c}
\hline & Hospitalization & $\begin{array}{c}\text { School Sick } \\
\text { Days }\end{array}$ & $\begin{array}{c}\text { Health Status: } \\
\text { Excellent }\end{array}$ & $\begin{array}{c}\text { Emotional } \\
\text { Difficulties }\end{array}$ \\
\hline Panel A: DJIA Index & & & & $-0.048^{*}$ \\
\hline Ln average daily close, DJIA & $-0.049^{* * *}$ & -0.736 & $0.084^{*}$ & $(0.024)$ \\
& $(0.011)$ & $(0.528)$ & $(0.018)$ & 61,657 \\
$N$ & 171,465 & 56,844 & 171,479 & 0.051 \\
\hline
\end{tabular}

Notes: All models include controls for race, gender, child's age, mother's age, mother's education, mother's marital status, household income, employment status, insurance status, and indicators for year and month. Robust standard errors clustered by year are in parentheses.

$* * * \mathrm{p}<0.01, * * \mathrm{p}<0.05, * \mathrm{p}<0.1$ 